\title{
ESTÁGIO E LITERATURA: UMA ABORDAGEM INTERDISCIPLINAR E REFLEXIVA
}

\author{
PASANTÍA Y LITERATURA: UN ABORDAJE INTERDISCIPLINARIO Y \\ REFLEXIVO
}

\author{
TRAINING AND LITERATURE: AN INTERDISCIPLINAR AND \\ REFLECTIVE APPROACH
}

Marilda Vinhote BENTES ${ }^{1}$

RESUMO: Este artigo consiste em um relato de experiência a partir da aplicabilidade do Projeto "Estágio e Literatura: uma abordagem interdisciplinar e reflexiva", executado no Instituto Federal de Educação, Ciência e Tecnologia de RoraimaIFRR/Campus Boa Vista, no ano de 2016, nos Módulos V e VI, do Curso Licenciatura em Letras-Espanhol e Literatura Hispânica. O trabalho teve como objetivo principal oferecer um processo interdisciplinar com foco na pesquisa e prática do ensino de língua espanhola, envolvendo os movimentos literários com sufixo -ismo. Para tanto, utilizou-se, como metodologia, um estudo de caso, por meio do Componente Curricular Estágio I e II: Pesquisa e Prática no Ensino Fundamental $\left(6^{\circ}\right.$ ao $9^{\circ}$ Ano), com aplicabilidade de aulas teóricas e práticas, bem como o uso de aulas dialogadas, orientações e supervisões. Tal docência amparou-se na abordagem funcionalista da língua, segundo Givón (1979) e Bybee (2010), tendo a literatura, por meio dos ismos, como guia condutor para o sucesso em sala de aula, a partir das ideias de Nogueira (2008). Ambas as bases teóricas foram vislumbradas pelas atividades de estágio para um fazer pedagógico significativo, conforme descrito por Barreiro e Gebran (2006) e outros autores relevantes a este trabalho. A experiência permitiu que no decorrer do processo a docente agisse como mediadora e, os acadêmicos, como protagonistas do processo de ensino-aprendizagem.

PALAVRAS-CHAVE: Estágio. Literatura. Funcionalismo. Abordagem reflexiva.

RESUMEN: Este artículo consiste en un relato de experiencia a partir de la aplicación del Proyecto: "Pasantía y Literatura: un abordaje interdisciplinario y reflexivo" llevado a cado en el Instituto Federal de Educação, Ciência e Tecnologia de RoraimaIFRR/Campus Boa Vista en los Módulos V y VI del Curso de Licenciatura en LetrasEspañol y Literatura Hispánica, durante el año 2016. El principal objetivo del trabajo consistía en ofrecer un proceso interdisciplinario con foco en la investigación y práctica de la enseñanza de lengua española, que involucraba los movimientos literarios con el sufijo 'ismo'. Para ello se utilizó como metodología un estudio de caso por medio del Componente Curricular Pasantía I y II: Investigación y Práctica en la Enseñanza Fundamental (sexto al noveno años), con aplicabilidad de clases teóricas y

${ }^{1}$ Instituto Federal de Educação, Ciência e Tecnologia de Roraima (IFRR), Boa Vista - RR - Brasil. Professora Mestre do Curso Licenciatura em Letras - Espanhol e Literatura Hispânica, do Departamento de Graduação. ORCID: <http://orcid.org/0000-0001-9004-7870>. E-mail: marilda.bentes@ifrr.edu.br. 
prácticas, además del uso de clases dialógicas, orientaciones y supervisión. Tal actuación se amparó en el abordaje funcionalista de la lengua según Givón (1979) y Bybee (2010), y en la literatura que trata de los 'ismos', como guía conductor para el éxito en la sala de clase, a partir de las ideas de Nogueira (2008). Ambas bases teóricas se visualizaron en las actividades de pasantía para un quehacer pedagógico significativo, conforme describe Barreiro y Gebran (2006) y otros autores relevantes. La experiencia permitió que, durante el processo, la docente actuara como mediadora, y los académicos, como protagonistas del proceso de enseñanza-aprendizaje.

PALABRAS CLAVE: Pasantía. Literatura. Funcionalismo. Reflexivo.

ABSTRACT: This article consists of an experience report from the applicability of the project "Training and Literature: an interdisciplinar and reflective approach", executed at the Federal Institute of Education, Science and technology of Roraima-IFRR/ Boa Vista Campus in 2016, in the fifth and sixth semesters, of the Course in Spanish and Hispanic literature. The main point of the work was to offer an interdisciplinary process focusing on the research and practice of teaching Spanish, involving literary movements with the 'ism ' suffix. As a methodology for that, a case of study was used, through the curricular component called Training I and II: Research and Practice in elementary School (6 ${ }^{\text {th }}$ to $9^{\text {th }}$ grade classes), with applicability of theoretical and practical lessons, as well as the use of dialogued classes, orientations and supervision. Such teaching was based in the functionalistic approach of the language, according to Givón (1979) and Bybee (2010), having literature, through the 'isms ', as a conductor guide for success in the classroom, from the ideas of Nogueira (2008). Both theoretical bases were glimpsed by the training activities for a meaningful pedagogic practice, as described by Barreiro and Ayman Galal (2006) and other relevant authors to this work. The experience allowed the teacher to act as a mediator, and that the students as protagonists in the teaching-learning process.

KEYWORDS: Training. Literature. Functionalism. Reflective.

\section{Introdução}

O objetivo deste artigo é realizar um estudo reflexivo acerca de uma experiência de ensino, a partir do Projeto Estágio e Literatura: uma abordagem interdisciplinar e reflexiva, desenvolvido inicialmente na turma do Módulo $\mathrm{V}$ e, posteriormente com a mesma turma, no Módulo VI, do Curso de Licenciatura em Letras-Espanhol e Literatura Hispânica-LELH, do Instituto Federal de Educação, Ciência e Tecnologia de Roraima IFRR/Campus Boa Vista - RR, o qual propôs como meta principal oferecer um processo interdisciplinar com foco na pesquisa e prática do ensino de língua espanhola, envolvendo os movimentos literários com sufixo -ismo, como: Afrocubanismo, Criollismo, Cubismo, Creacionismo, Futurismo e Ultraísmo. 
O projeto fez-se necessário por vários motivos; dentre eles, está a proposta do Plano de Curso da referida Licenciatura, pois expõe que o curso está fundamentado tanto em conhecimentos linguísticos quanto em culturais, em que sua intencionalidade preza pela comunicação de ideias, significados, informações, pelas relações entre culturas e pelo envolvimento dos componentes curriculares, dentre outros aspectos da realidade social. Por isso, é imprescindível que os futuros docentes desenvolvam, no período de estágio, estudos, pesquisas, reflexões, planejamentos e regências com foco no ensino de língua espanhola, amparado no uso da literatura em uma perspectiva intercultural e de acordo com a realidade.

Assim, a proposta percebe a literatura como um novo posicionamento estratégico, como cenário cognitivo, histórico, cultural e social, para atribuir sentidos ao uso da língua espanhola. Com isso, o acadêmico passa a compreender o processo histórico, político, econômico, social e geográfico, para usufruir da dinâmica de contexto e gramática que sustenta o uso da língua espanhola (LE), a partir da teoria funcionalista da linguagem, tornando-o capaz de refletir sobre o texto e de utilizá-lo em sala de aula para discutir, relatar, interagir, produzir e aprender sobre o tema estudado.

Dessa forma, preconiza-se proporcionar uma formação docente específica para adquirir as habilidades inerentes ao ensino de espanhol como língua estrangeira, uma vez que o ensino de literatura, dentro da perspectiva proposta, configura uma via de integração de conhecimentos que favorece a aprendizagem e busca um enfoque atrativo em uma disciplina tão clássica para consolidar os conhecimentos linguísticos e culturais.

Portanto, para esta conjuntura, é fundamental fomentar discussões em meio acadêmico sobre a importância que a literatura possui e como utilizá-la em prol da melhoria do ensino, pois o conhecimento literário está atrelado ao processo do ensinoaprendizagem de uma língua. É necessário que a literatura seja trabalhada em sala de aula não apenas como simples base para o ensino gramatical, mas como estratégia para um trabalho além do conhecimento linguístico, no qual tanto o futuro professor quanto o aluno sejam beneficiados com subsídios para ações reflexivas que sustentem a vivência cotidiana.

\section{Estágio e literatura: uma abordagem interdisciplinar e reflexiva}


Segundo o Regulamento Geral para a realização de Estágio Curricular Supervisionado dos cursos do Instituto Federal de Roraima-IFRR, o estágio deve propiciar ao discente a participação em situações reais que envolvam a relação entre teoria e prática, mesmo porque o estágio é um ato educativo com ênfase didáticopedagógica, que visa à preparação do futuro profissional para o mundo do trabalho (IFRR, 2017).

Nesse sentido, a área pedagógica de uma licenciatura precisa articular um trabalho que envolva uma síntese de todos os componentes curriculares para subsidiar o processo de ensino-aprendizagem na escola-campo, fazendo uma interação entre o indivíduo e o processo cultural que abrange a língua espanhola. Para tanto, o estágio precisa ser percebido como meio de confrontação, reflexão e tomada de decisão, fortalecendo na prática o que o acadêmico vivenciou durante sua formação, já que é no processo de formação que "[...] são consolidadas as opções e intenções da profissão que o curso se propõe legitimar [...]" (PIMENTA; LIMA, 2004, p. 62).

As aulas de estágio em um curso de formação devem proporcionar espaços de aprendizagem em uma relação investigativa e reflexiva, em que cada estratégia desenvolvida é pensada a partir da realidade dos futuros professores e do sistema educacional no qual desenvolverão as atividades de estágio. Ao compreender as necessidades do alunado, o docente orientador direcionará o acadêmico a um processo reflexivo para conduzir com autonomia suas ações enquanto estagiário. A esse respeito, Barreiro e Gebran (2006) afirmam que:

[...] a formação inicial e o estágio devem pautar-se pela investigação da realidade, por uma prática intencional, de modo que as ações sejam marcadas por processos reflexivos entre os professores-formadores e os futuros professores, ao examinarem, questionarem e avaliarem criticamente o seu fazer, o seu pensar e a sua prática (2006, p. 21).

Para as autoras, teoria e prática são indissociáveis, remetendo o futuro profissional a refletir acerca dos conteúdos a serem ensinados, uma vez que é imprescindível trazer a realidade globalizada, moderna e informatizada para sala de aula. Então, a busca é por atribuir significado aos conteúdos programáticos, pois é o docente quem deve proporcionar condições para favorecer a construção de conhecimento por parte do aprendiz.

Como resultado, para Libâneo (2012, p. 83), “[...] a apropriação teórica da realidade implica o desenvolvimento dos processos do pensar em relação aos 
conteúdos”. Por isso, a importância da pesquisa no estágio de observação, já que esta dará suporte para planejar a regência, ou seja, para a elaboração de um "[...] projeto de atividades que forneça um eixo integrador necessário para a interdisciplinaridade [...]" (GARCIA, 2008, p. 371). Assim, de acordo com Libâneo (2012), o acadêmico passa a estruturar suas ideias e analisar seus próprios processos, propondo uma ação prática marcada por valores, que requer leitura crítica da realidade para um fazer pedagógico eficaz.

Corroborando com tais afirmativas, o Plano de Curso da Licenciatura LELH expõe que, no curso, são ofertados componentes curriculares voltados para:

[...] reflexão sobre o ensino-aprendizagem de línguas estrangeiras e literatura na Educação Básica (Ensino Fundamental II e Ensino Médio) e sobre a formação docente. O estágio curricular constitui também espaço privilegiado de síntese de saberes acadêmicos e de conhecimentos originados da experiência no cotidiano escolar (IFRR, 2015, p. 7).

Ao considerar a realidade do curso de formação ora exposto, os movimentos literários com sufixos -ismos, por tratarem de manifestações em resposta à realidade política, econômica e social, são conteúdos capazes de agregar pensamentos filosóficos e ideologias de sua origem com os da atualidade, permeando os conteúdos programáticos da disciplina de Língua Espanhola.

Entretanto, é correto afirmar que trabalhar com literatura, utilizando gêneros literários, por exemplo, é desafiador, pois, a tendência é que a estratégia utilizada se torne monótona e, portanto, sem significado para os discentes, mesmo porque, segundo Nogueira (2008, p. 162), há algumas dificuldades com o uso dos textos literários nas aulas de língua estrangeira, uma vez que é necessário o hábito da leitura para desenvolver uma atividade proposta pelo livro didático, com os seguintes objetivos:

[...] 1) responder a questões que induzem o aluno a repetir as mesmas estruturas do texto; 2) reforçar algum aspecto gramatical presente nele; 3) ampliar o vocabulário; 4) produzir outro texto; 5) destacar um determinado aspecto cultural. (NOGUEIRA, 2008, p. 162)

De acordo com a autora, trabalhar com texto literário vai além desses objetivos, pois requer principalmente que o aluno interaja com o texto, “[...] observando as relações que mantém com o contexto sócio-cultural e com outros textos, para poder vivenciá-los integralmente [...]" (NOGUEIRA, 2008, p. 163). É possível que os alunos apresentem mais dificuldades na compreensão dos gêneros literários, mas o suporte 
deve ser dado para que o aprendiz tenha "[...] compreensão de que o texto literário difere de qualquer outro devido suas especificidades, pois sua linguagem [...] é essencialmente conotativa, ambígua, irônica, paradoxal" (NOGUEIRA, 2008, p. 163), gerando uma multiplicidade de interpretações por parte dos leitores.

Assim, os cursos de formação precisam direcionar, por meio das disciplinas que envolvem língua e literatura, uma abordagem teórica significativa, para que no momento da prática, os estagiários tenham uma compreensão significativa dos conteúdos a serem ensinados, já que o futuro docente, na regência, será o mediador - ou seja, é ele que irá selecionar textos significativos e estimuladores, oferecendo possibilidades de estratégias que contemplem pesquisas, debates, dramatizações e outras, com temas relevantes para despertar interesse. Ressalta-se, contudo, que, sem o conhecimento teórico, o futuro docente pode não conseguir aproveitar os textos ou a própria temática a ser trabalhada, deixando de incentivar as reflexões e debates sobre os aspectos linguísticos e as características culturais, políticas, econômicas e sociais.

Na proposta que versa sobre o estágio e o uso da literatura no ensino da língua espanhola, há a necessidade de delinear uma abordagem teórico-metodológica que dê respaldo ao estudo do papel do indivíduo e da função que a língua exerce no ato de comunicar, relacionando o texto e o contexto comunicativo, ou seja, que considere uma relação da estrutura gramatical com a função que o texto exerce na comunicação interpessoal. Por isso, assume-se a abordagem funcionalista, isso porque, segundo Givón (1979) e Bybee (2010), converge para o fato de que a estrutura da língua emerge da língua em uso, em que há negociação de sentidos atrelados à forma linguística.

Os Parâmetros Curriculares Nacionais - PCNs (1998, p. 15), nessa esteira, expõem que há a necessidade de um ensino baseado na interação, no uso social e efetivo da língua, na maneira como o aprendiz emprega seu conhecimento gramatical, dentre outros que envolvem o processo comunicativo, permitindo um educador mediador e um aluno ativo.

Portanto, segundo Givón (1979), o estudo da estrutura linguística é indissociável do uso da língua pelo falante. Com base nisso e mediante as orientações pedagógicas presentes nos PCNs (1998), a língua é sujeita ao dinamismo discursivo pragmático, em que gramática e discurso vivem uma relação de simbiose.

\section{Descrição e análise da experiência}


Desde 2014, vem sendo desenvolvido um trabalho com orientação de estágio supervisionado no Curso de Licenciatura em Letras-Espanhol e Literatura Hispânica, do Instituto Federal de Educação, Ciência e Tecnologia de Roraima - IFRR/Campus Boa Vista, propondo em cada turma ações diferenciadas para que os futuros docentes viessem logrando êxito no processo. Assim, para desenvolver a experiência descrita neste texto, utilizou-se um estudo de caso, no ano de 2016, a partir da articulação dos docentes de Estágio, de Língua Espanhola e de Literatura, pondo em prática o projeto Estágio e Literatura: uma abordagem interdisciplinar e reflexiva.

No primeiro momento, a proposta foi direcionada à turma do Módulo $\mathrm{V}$, pois a etapa correspondia ao estágio de observação, sendo ela crucial para a eficácia das fases posteriores, pois é nela que o futuro docente tem o contato com a dinâmica escolar, permitindo-se uma participação reflexiva e investigadora diretamente no campo de estágio. Neste sentido, as aulas presenciais, no IFRR/Campus Boa Vista, deram-se de forma interdisciplinar, iniciando pelo estudo dos elementos que constituem um planejamento e direcionando textos da área pedagógica, da linguística e da literatura para embasar os trabalhos durante o trajeto de estágio. Afinal, este “[...] deve contemplar a formação do professor capaz de atender às demandas de uma realidade que se faz nova e diferente a cada dia” (BARREIRO; GEBRAN, 2008, p. 91).

A partir da base legal e teórica acerca do estágio, da língua e da literatura, e para atender futuramente as demandas da dinâmica escolar, os acadêmicos elaboraram um plano de estágio, considerando os recursos didáticos, o Projeto Político-Pedagógico, metodologia, relações interpessoais e reuniões pedagógicas, dentre outros itens, já que na observação é necessário um olhar atento para a realidade explícita e implícita, tendo claramente o objeto de pesquisa bem definido. Obtêm-se, assim, registros significativos para atuar no processo de ensino-aprendizagem.

Durante quarenta horas, os estagiários realizaram suas pesquisas nas escolascampo, registrando os aspectos que constituem o contexto social e histórico em que a escola está inserida. Ao final, após a entrega do relatório de estágio e para consolidar o observado, realizou-se uma socialização, na qual cada acadêmico demonstrou sua percepção da realidade. Nesse momento, eles foram indagados a partir da própria fala, com direcionamentos para a elaboração do projeto de intervenção a ser posto em prática no Módulo VI.

Como prosseguimento das aulas no IFRR/Campus Boa Vista, retomou-se uma discussão acerca de currículo de língua estrangeira no ensino fundamental, pontuando o 
que observaram na escola e como a língua deve ser concebida, ou seja, como um fenômeno sociocultural em que as mudanças ocorrem por meio de seu uso nas práticas sociais. Com isso, os futuros docentes manifestaram receio acerca de como envolver a literatura que já vinha sendo trabalhada de forma teórica pela docente do componente curricular.

Após essa discussão, foi solicitado que os acadêmicos produzissem em grupo um mapa conceitual a partir dos movimentos literários com sufixo -ismo. Cada equipe, em meio à expectativa do resultado, usou da criatividade para elaborar seu mapa. Tentaram, inclusive, imaginar como fariam esse processo em sala de aula do Ensino Fundamental. Com isso, confeccionaram uma diversidade bastante significativa de mapas conceituais, utilizando flores, formas geométricas, mapa digital, colagem e mosaico, como pode ser visto no exemplo abaixo:

\section{Figura 01: Mapa conceitual}

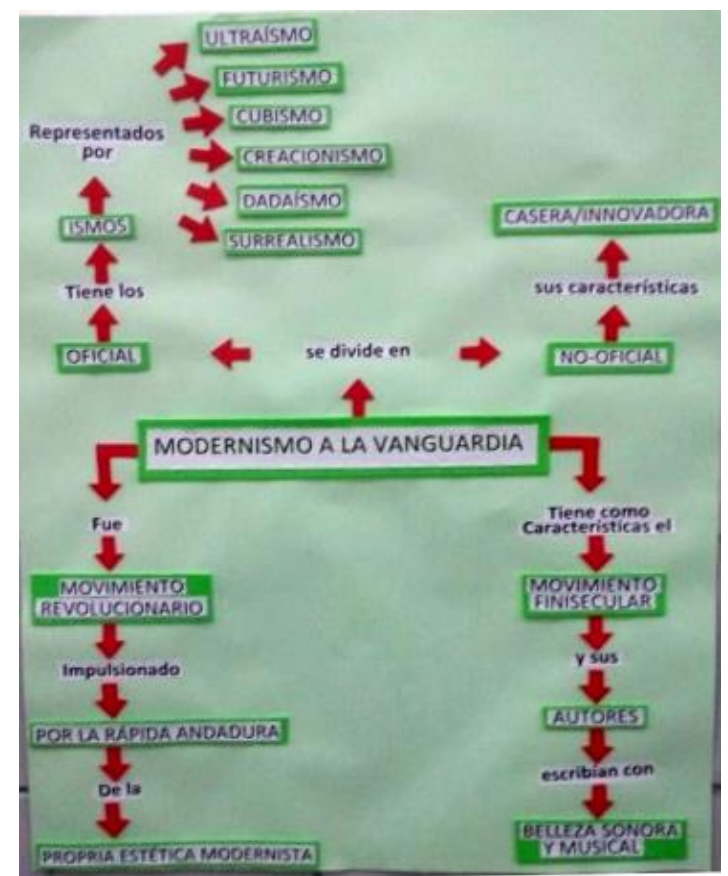

Fonte: Repositório da autora deste artigo (2016)

Mesmo com a produção e exposição dos trabalhos aos visitantes, os futuros docentes não compreendiam como desenvolveriam as aulas com alunos do Ensino Fundamental, pois na visão deles o trabalho seria desenvolvido da mesma forma que a faculdade trabalha com eles. Neste sentido, a fala dos acadêmicos era quase unânime: não conseguiriam ministrar aulas a partir do movimento literário. 
Diante de tal situação, foi ministrada uma microaula pela orientadora de estágio, mostrando uma sequência didática e de conteúdo, utilizando o livro de poemas regionalista e modernista "Morte e Vida Severina", de João Cabral de Melo Neto, por meio de trechos selecionados, que serviram de base para trabalhar o contexto da produção da obra. Após a montagem e leitura do texto, foi colocada como música de fundo "Planeta Água", de Guilherme Arantes. Para garantir a eficácia do trabalho, a docente fez um link entre os dois textos, fazendo menção à realidade e ao texto " $\mathrm{O}$ fantasma da sede", da National Geographic Brasil, 2001, escolhendo trechos para trabalhar a realidade, análise linguística e relação entre culturas e, ainda, usando como recurso o livro didático para distinguir os gêneros trabalhados.

Essa aula foi para que os envolvidos tivessem uma noção do que poderia ser trabalhado a partir de um ou mais gêneros textuais em distintos dias, ressaltando o funcionalismo a partir da simbiose existente entre a estrutura gramatical e distintos contextos, por exemplo, ao fazer inferências com base no título "O fantasma da sede", ou tentar compreender a realidade cultural do povo nordestino. Nesse momento, vários conteúdos e estratégias foram sugeridos pelos acadêmicos, que começaram a realizar a articulação entre o conhecimento de mundo e o formal, mostrando que as ideias ficaram mais coerentes com a proposta. Ainda era visível, porém, o receio de levar o movimento literário para a sala de aula.

Salienta-se que, mesmo com a insegurança, iniciou-se a produção do projeto de intervenção. Para tanto, foi realizada uma aula em que cada aluno falou da maior dificuldade encontrada no processo ensino-aprendizagem no estágio de observação, ocasião em que alguns expuseram o desinteresse por parte do aluno e o desprestígio da disciplina. Porém, ao serem instigados mais a fundo, outros aspectos - inclusive com exemplos - começaram a ser expostos, como: pronúncia, o uso de $l l$, leitura, desrespeito.

Ainda, ao considerar a investigação, os alunos escolheram o movimento literário e elencaram, a partir dele, um gênero e uma temática/eixo para trabalhar em sala de aula. Entretanto, frisou-se que não trata de excluir, por exemplo, para quem escolheu a pronúncia, as demais destrezas, mas sim focar em uma das habilidades em que as outras fluirão sem muito esforço, visto que não há como separá-las, mas há como trabalhar com mais ênfase nas características de determinadas dificuldades. No momento de listar os conteúdos culturais e gramaticais houve certa euforia, em que a ampla maioria dos acadêmicos queria listar inúmeros conteúdos, mesmo cientes de que disporiam de 
apenas quarenta horas de docência, tempo que não contribuía para o desenvolvimento de um trabalho com muitos conteúdos.

Esse processo de construção seguiu guiando-os para elaboração dos objetivos e demais elementos que constituem o projeto, encadeando as ideias para um processo que envolve tanto questões socioculturais quanto gramaticais. A partir dos conteúdos listados, houve encontros individuais para elaboração e apresentação de uma aula de cinquenta minutos que demonstrasse conhecimento acerca do texto escolhido, em termos linguísticos e culturais.

Desse modo, cumpriu-se um dos objetivos dispostos no Plano de Curso, que é formar docentes para atuar na Educação Básica “[...] a partir de uma perspectiva curricular interdisciplinar que segue novos preceitos de ensino, combinando a prática docente ao contexto e às necessidades da sociedade." (IFRR, 2015, p. 14). Esta etapa concluída foi motivo de orgulho para todos, pois houve evolução e ampliação de conhecimento para a docente, porque visualizou o empenho e a superação dos alunos, e para os estagiários, que conseguiram, com muito estudo e dedicação, avançar nas estratégias propostas, vencendo as dificuldades encontradas.

No segundo momento, a proposta foi direcionada à mesma turma, porém já no Módulo VI, pois a etapa correspondia ao estágio de regência. Ainda eram visíveis a ansiedade e o receio de pôr em prática o que foi proposto no Módulo $\mathrm{V}$, mas a ideia passou a ser elaborar os planos de aula a partir do projeto. Após alguns exemplos, a criatividade tomou conta dos grupos, que passaram a construir suas aulas de maneira mais autônoma, tendo a liberdade de tirar dúvidas e pedir auxílio quando as ideias não avançassem.

Munidos do projeto e de pelo menos dois planos de aula, os estagiários ${ }^{2}$ iniciaram o Estágio II: Regência no Ensino Fundamental ( $6^{\circ}$ ao $9^{\circ}$ Ano). Dentre os relatos, o grupo Alfa expôs que foi significativo ir à escola com um planejamento coerente com a realidade, seguindo uma sequência didática de maneira contextualizada e intercultural. É fato que para os PCNs (1998) o docente deve considerar a análise dos conhecimentos de mundo como fonte primária de informações, pois a articulação desses distintos saberes é relevante para organizar um planejamento eficaz, que demonstre o caminho a ser seguido.

${ }^{2}$ Cada equipe de estagiários receberá um nome fictício para facilitar a leitura. 
Mesmo com todo o processo de estudo e planejamento houve relato do grupo Arte, que ministrou aulas sobre Pop Art, por meio de um curso livre ${ }^{3}$, posterior ao primeiro dia de aula. Ficou evidenciado que ainda existia uma expectativa quanto à proposta, no sentido de, até pelo inusitado, saber sobre o resultado que podiam obter com a aplicação do projeto, pois estavam preocupados com o comportamento dos discentes, isto é, como iriam reagir diante do movimento literário e a forma como iriam expor seus conhecimentos, uma vez que seu público não era do ensino regular, mas da comunidade em geral.

Após a terceira aula, o grupo Arte relatou que as discussões sempre proporcionaram momentos saudosistas, antigos às vezes, tradicionais em outras, mas sempre mesclando falas voltadas para a juventude de quarenta anos atrás com o que se conhece das novas técnicas e didáticas oferecidas e praticadas pelo ensino atual. Esse fato os favoreceu muito na qualidade de futuros professores, pois nunca se omitiram de seu papel. Pelo contrário estudaram com mais afinco para compartilhar informações e experiências que, de alguma forma, contribuíam para o avanço dos saberes entre os envolvidos.

A equipe Beta expôs que, ao iniciar o processo de escolha dos textos para trabalhar sobre Afrocubanismo, constatou o quanto o movimento era rico, ainda mais ao trabalhar temas da cultura negra, perpassando as questões de preconceito e a realidade brasileira. Em meio à discussão, optou-se por escolher textos atuais, como o cuento "Un chocolate muy especial" e a música "Esclavo de Job", usando as informações dos textos sobre o movimento literário como suporte nas aulas. Segundo as estagiárias, isto estimulou os alunos a se pronunciarem, arriscando palavras e até frases simples em espanhol, estratégia amparada no funcionalismo, defendido por Bybee (2010), cujo princípio fundamental é a premissa de que a estrutura linguística emerge da língua em uso.

Cabe salientar que o grupo Beta escolheu dois gêneros distintos, um cuento e uma canción, para desenvolver suas aulas, mas incrementou os conteúdos programáticos, literários e culturais com a realidade e estratégias lúdicas. Para a equipe, não houve resistência nas turmas; pelo contrário, obteve-se adesão total com participação ativa dos aprendizes em cada atividade.

${ }^{3}$ Os cursos livres do IFRR/Campus Boa Vista são ações de extensão, neste caso, de natureza didáticopedagógica, desenvolvido no âmbito do curso superior, em uma ação comunitária na perspectiva de prática profissional enriquecedora da formação acadêmica, veiculadora da retroalimentação do ensino e viabilizadora da intervenção institucional na sociedade. 
O Cubismo foi trabalhado pelo grupo Ômega. Para ministrar as aulas, escolheram duas obras de arte: "A Conquista de Ar", de Juan Gris, e "Les Demoiselles d'Avignon", de Pablo Picasso. Segundo o planejamento e o relatório, a equipe iniciou a sequência didática a partir da leitura coletiva das duas obras citadas, listando as falas em espanhol no quadro, pronunciando-as após cada escrita. Com um número considerável das inferências vislumbradas nas obras, começaram a questionar o contexto de produção da época, dando direcionamento às falas para relacioná-las com a Semana da Arte Moderna. Nesse processo, as características do ismo em foco fizeram com que se pensasse em utilizar como recursos quebra-cabeça e mosaico, este último usado para a produção dos alunos, pois além da produção do mosaico, teria que produzir frases que correspondessem à obra.

Outro momento bastante significativo e que cabe neste artigo, foi na supervisão do estágio de regência, no qual a aula relatada foi a do grupo Master, sobre o movimento Criollismo. Esse grupo sempre foi o que mais dizia que não iria conseguir, mesmo com um planejamento alicerçado em bons textos e estratégias dinâmicas.

No dia da visita, a técnica da aula era bem simples, mas com aprofundado teor de informações. Quando a supervisora entrou na sala, a aula já estava em curso. Havia um pequeno trecho no quadro, em espanhol, sobre a ascensão do Criollismo. Abaixo, estavam finalizando um glossário de palavras existentes no texto, mas a preocupação era que os sentidos partissem do texto produzido, não de um dicionário. Os aprendizes expressavam suas ideias e complementavam com comparações e questionamentos. Afinal, a temática do projeto estipulado pelo grupo era respeito e o grande obstáculo era a falta de respeito. A aula superou as expectativas.

No relatório da equipe Master, ficou evidenciada a certeza de que ser um professor é uma escolha de compromisso verdadeiro, em que se deve ensinar, educar e ter sempre um olhar especial para cada aluno, que somente assim entenderá o seu aprender. Essa reflexão surgiu de todo contexto que vivenciaram. Inclusive, só conseguiram perceber a partir da própria docência que realmente o trabalho daria certo.

Cabe ressaltar que, no dia da apresentação de todo o processo de estágio para uma banca composta por três docentes, sendo a professora orientadora, uma docente interna da área de língua e literatura e uma docente externa da área de língua, os relatos e o entusiasmo dos futuros docentes causaram emoção. O discurso emocionado de uma integrante da equipe Master foi muito expressivo, evidenciando que o objetivo que chegou a parecer inatingível resultou para elas no ápice do processo acadêmico. 


\section{Considerações finais}

Com base no exposto é possível afirmar que em Estágio I e II houve reconhecimento e aplicação das teorias aprendidas no curso de formação, a partir da pesquisa e da execução do projeto de intervenção, respondendo às necessidades do ensino de língua espanhola, com contextos e conteúdos distintos.

A experiência ora exposta teve seu objetivo alcançado, pois as aulas no IFRR/Campus Boa Vista foram desenvolvidas por meio de um processo interdisciplinar, a partir das disciplinas de Estágio, Literatura e Língua Espanhola, em que a pesquisa e a prática foram o foco e a descoberta de um olhar estratégico para um fazer pedagógico coerente, consistente e intencional diante da realidade escolar, social e cultural em que as escolas estão inseridas.

Os ismos tornaram-se o suporte essencial para que emergissem os conteúdos linguísticos e culturais que favoreceram a participação ativa dos aprendizes das escolascampo, bem como o protagonismo, a autonomia e certa identidade profissional aos estagiários. Compreendeu-se que o estudo, uma boa base teórica, o conhecimento da realidade e um planejamento coeso são imprescindíveis para um profissional compromissado. Sobreveio ainda, para a docente orientadora, a certeza de que o novo incomoda, mas ao acreditar nas possibilidades de ser mediadora no processo, a construção de conhecimento flui em uma ação-reflexão-ação.

\section{REFERÊNCIAS}

BARREIRO, I. M. de F. GEBRAN, R. A. Prática de ensino e estágio supervisionado na formação de professores. São Paulo: Avercamp, 2006.

BRASIL. Parâmetros Curriculares Nacionais: $3^{\circ}$ e $4^{\circ}$ Ciclos do Ensino Fundamental. Brasília: Ministério da Educação. Secretaria da Educação Fundamental, 1998.

BYBEE, J. Language, usage and cognition. Cambridge: Cambridge University Press. 2010.

GARCIA, J. A. Interdisciplinaridade segundo os PCNs. Revista de Educação Pública, Cuiabá, v. 17, n. 35, p. 363-378, set./dez. 2008.

GIVÓN, T. On Understanding Grammar. New York: Academic Press, 1979.

IFRR - INSTITUTO FEDERAL DE EDUCAÇÃO, CIÊNCIA E TECNOLOGIA DE RORAIMA. PPC Letras Espanhol e Literatura Hispânica. In: Laurido, E. D. (Org.). 
Plano Pedagógico do Curso de Licenciatura em Letras Espanhol e Literatura Hispânica. Boa Vista: 2015. p. 11-23.

IFRR - INSTITUTO FEDERAL DE EDUCAÇÃO, CIÊNCIA E TECNOLOGIA DE RORAIMA. Resolução do Conselho Superior do IFRR n 292, de 5 de maio de 2017. Dispõe sobre o Regulamento Geral para Realização de Estágio Curricular supervisionado dos Cursos do Instituto Federal de Educação, Ciências e Tecnologia de Roraima (IFRR). Boletim de Pessoal e Serviço da Reitoria do IFRR, Boa Vista, RR, n. 23, 2017.

LIBÂNEO, J. C. Reflexividade e formação de professores: outra oscilação do pensamento pedagógico brasileiro. In.: PIMENTA, S. G.; GHEDIN, E. (Org.). Professor reflexivo no Brasil: gênese e critica de um conceito. 7. ed. São Paulo: Cortez, 2012. p. 63-93.

NOGUEIRA, S. R. O papel da literatura no ensino de LE. In.: DURÃO, A. B. ANDRADE, O. G.; REIS, S. (Org.). Reflexões sobre o ensino das línguas estrangeiras. Londrina: UEL, 2008. cap. 7, p. 159-182.

PIMENTA, S. G.; LIMA, M S. L. Estágio e docência: planejando o estágio em forma de projetos. $2^{\text {a }}$ ed. $2^{\text {a }}$ parte. 2004.

\section{Como referenciar este artigo}

BENTES, M. V. Estágio e literatura: uma abordagem interdisciplinar e reflexiva. Rev. EntreLínguas, Araraquara, v.4, n.1, p. 17-30, jan./jun. 2018. E-ISSN: 2447-3529. DOI: 10.29051/rel.v4.n1.2018.10897.

Submetido em: 30/11/2017

Revisões requeridas: $14 / 03 / 2018$

Aprovação final em: 12/04/2018 